\title{
DOS CONVENTOS E RECOLHIMENTOS PARA OS COLÉGIOS DE FREIRAS: AS DIFERENÇAS DA EDUCAÇ̃̃O FEMININA CATÓLICA NOS SÉCULOS XVIII E XIX
}

\author{
Ana Cristina Pereira Lage* \\ Universidade Federal dos Vales do Jequitinhonha e Mucuri (UFVJM), Diamantina - MG, Brasil
}

RESUMO: Este artigo analisa os princípios educativos da Igreja Católica nas especificidades das instituições confessionais femininas brasileiras nos séculos XVIII e XIX. Apresenta os resultados de uma pesquisa acerca da educação instituída no interior dos conventos, lugares para uma vida perfeita, e agregados às ordens monásticas do século XVIII, caracterizada por um modo de vida claustral e pela educação devocional. No século XIX, devido à ampliação dos discursos da escolarização feminina e dos anseios de fortalecimento da Igreja Católica com o auxílio da devoção das mulheres, articula-se um novo modelo educativo confessional, instituído pela entrada das congregações de vida ativa no Brasil e a instalação de colégios para a educação de meninas, futuras mães e esposas. Salienta-se a importância desta pesquisa para discutir as diferenças e as continuidades entre os dois modelos propostos e compreender como a Igreja Católica articulou a educação feminina por meio de ordens e congregações religiosas.

Palavras-chave: Educação Feminina. Igreja Católica. Freiras.

FROM CONVENTS AND GATHERINGS TO NUNS' SCHOOLS: THE DIFFERENCES IN WOMEN'S CATHOLIC EDUCATION IN THE XVIII AND XIX CENTURIES

ABSTRACT: This paper analyzes the educational principles of the Catholic Church into specificities of the Brazilian feminine confessional institutions from the XVII and XIX century. We present a research's results about the education established in the interior of the convents, places for a perfect life, and gatherings into monastic orders from the XVIII century, characterized by a cloistral lifestyle and devotional education. In the XIX century, due to the enlargement of feminine schooling speeches and the aspirations for a stronger Catholic Church with the assistance of women's devotion machinates a new confessional educational model, settled by the

http://dx.doi.org/10.1590/0102-4698153698

* Doutora em Educação pela Universidade Federal de Minas Gerais. Professora Adjunta dos cursos de Licenciatura em História e Mestrado Profissional Interdisciplinar em Ciências Humanas da Universidade Federal dos Vales do Jequitinhonha e Mucuri, Campus Diamantina, Minas Gerais. Membro do Grupo de Pesquisa Cultura e Educação na América portuguesa. E-mail: < ana.lage@ufvjm.edu.br > . 
congregational active life's entrance in Brazil and the setup of educational schools for girls, future moms and wives. We emphasize the importance of this research in order to discuss the differences e continuities between the two proposed models and comprehend how the Catholic Church structured feminine education through orders and religious congregations.

Keywords: Women's Education. Catholic Church. Nuns.

\section{INTRODUÇÃO}

Em 1965, o Concílio Vaticano II, comandado por Paulo VI (Papa 1963-1978), publicou a Declaração Gravissimum Educationis (sobre a Educação Cristã). Esse documento pode ser considerado como um marco e um instrumento de base para a educação católica até os dias atuais. $\mathrm{O}$ documento propõe uma adaptação dos anseios da Igreja Católica acerca da educação às necessidades específicas do seu tempo e dos diversos espaços nos quais ela possui instituições educativas. Segundo o referido Concílio, cabe à Igreja Católica, de acordo com o mandato "estabelecido por Jesus Cristo em sua fundação", anunciar o "mistério da salvação" e "cuidar de toda a vida do homem", contribuindo assim para o progresso e a ampliação da educação e do catolicisma (CONCÍLIO VATICANO II, 1965).

De acordo com o documento, a família é considerada como a primeira instituição educativa para consolidar as virtudes sociais de que a sociedade tem necessidade. Mas considera que cabe principalmente à Igreja o caráter educativo, uma vez que esta deve ser reconhecida como "[...] sociedade humana capaz de ministrar a educação, mas sobretudo porque tem o dever de anunciar a todos os homens o caminho da salvação" (CONCÍLIO VATICANO II, 1965)

Verifica-se então que, dentro dos seus princípios educativos, algumas frentes dentro da própria instituição eclesiástica são consideradas importantes para a construção de um "católico perfeito": inicialmente, a instrução catequética e, além disso, outros meios que possam "cultivar as almas e formar os homens", exemplificados pelos meios de comunicação social, as organizações culturais e desportivas, além das próprias escolas (CONCÍLIO VATICANO II, 1965). Esse caminho de considerar vários tipos de possibilidades para a educação católica demonstra que esta possui um perfil educativo em diversas vertentes. Neste artigo, pretende-se analisar algumas vertentes educativas femininas no interior do catolicismo. Inicialmente, procura-se compreender a organização da educação no interior dos conventos e recolhimentos femininos do século XVIII 
e, posteriormente, como se constitui a fundação de escolas femininas instituídas por freiras no século seguinte em solo brasileiro.

Para não cometer nenhum anacronismo, uma vez que o artigo parte da citação de um documento do século XX e coloca em uma longa duração temporal as instituições aqui analisadas, torna-se importante salientar que, embora a escrita do Gravissimum Educationis seja uma expressão do seu tempo, também aponta relações e concepções acerca da educação que perpassa esse tempo e que reflete a participação da Igreja Católica no setor educativo desde a sua fundação.

Considerando as especificidades espaciais e temporais, as famílias, os conventos e recolhimentos ou as escolas confessionais tornam-se ambientes propícios para desenvolver a inteligência, o conhecimento e a formação do caráter dos educandos. Nesse sentido, o caráter que se pretende no ambiente educativo católico compreende principalmente a devoção a Deus. A religião é considerada uma parte essencial da educação, por sua centralidade do processo educativo nas instituições aqui analisadas: conventos, recolhimentos e escolas de freiras. Neste artigo, optou-se por trazer algumas especificidades educativas de duas instituições distintas brasileiras e que podem ser consideradas como modelares para as demais instituições que surgiram após as suas fundações: o primeiro convento de ordem religiosa feminina, o Convento de Santa Clara do Desterro de Salvador - BA (1677); e o primeiro Colégio de congregações femininas em solo brasileiro, o Colégio Providência das Filhas de Caridade de São Vicente de Paulo, de Mariana - MG (1849).

$\mathrm{Na}$ comparação entre as instituições devocionais femininas educativas do século XVIII e aquelas do século XIX, percebe-se uma diferenciação tanto na intencionalidade quanto na estruturação dos espaços educativos. Assim, no primeiro caso, os conventos eram lugares que propunham uma educação com a intencionalidade de reclusão feminina, especialmente com o intento de alcançar uma perfeição de vida religiosa da reclusa. Constituíam-se em espaços para poucas mulheres e a educação era voltada para o aprendizado das virtudes cristãs e para a celebração de atividades devocionais. Em outro sentido, quando as primeiras congregações religiosas chegaram ao Brasil em meados do século XIX, estas propunham uma nova prática educativa, com a intencionalidade de escolarizar meninas para prepará-las não só para a vida religiosa, mas também para exercer funções de esposas e mães, ou até para atividades de trabalho, dentro do modelo católico pretendido naquele momento. Também buscavam o aprendizado das virtudes cristãs e a celebração de atividades devocionais, mas se 
diferenciavam por desenvolvê-las para as famílias católicas. Enquanto nos setecentos fechavam e mantinham as mulheres reclusas, nos oitocentos, estas eram preparadas para o mundo externo, em uma tentativa de fortalecer o catolicismo por meio de suas ações familiares.

Faz-se importante compreender também as diferenças temporais com relação aos anseios para a educação feminina, uma vez que foi somente no final do século XVIII que ocorreu uma ampliação do discurso acerca da necessidade da escolarização feminina, encampada tanto pelos políticos liberais quanto pela própria Igreja Católica. Dentro dos princípios liberais, a escola funcionaria como o lugar de formação do homem político, capaz de ser inserir na coletividade, como lugar de formação para a moralidade, de conformação de regras para a conduta social e do civismo republicano. Em geral, a educação feminina aparecia essencialmente como mecanismo de preparo para se formar uma boa esposa e uma boa mãe para esse cidadão. É possível detectar que a necessidade de preparação da mulher para uma boa maternidade e para um casamento adequado também esteve presente no discurso católico acerca da ampliação da educação feminina. $\mathrm{O}$ que diferenciava o discurso político do discurso católico referente à educação feminina e à maternidade era o caráter natural do primeiro com relação ao caráter sagrado do segundo.

Salienta-se que este artigo trata de dois momentos distintos com relação à educação feminina, uma vez que, quando se fala da instituição de conventos e recolhimentos no século XVIII, a educação de mulheres ainda era um anseio de poucos, mas quando as congregações chegam ao Brasil a partir de meados no século XIX com a intenção de instituir colégios, estes se fortalecem também por meio da ampliação do discurso da necessidade de educar meninas.

Ressalta-se a importância desta pesquisa desenvolvida no interior do Grupo de Pesquisa Cultura e Educação na América Portuguesa e vinculada ao projeto "Instituições e práticas educativas na América Portuguesa no século XVIII e primeiras décadas do século XIX". A análise dos dois modelos aqui propostos pretende compreender as suas interseções, continuidades e rupturas. Salientase que, ao analisar outros estudos sobre a temática, percebe-se que a maior parte das pesquisas empreendidas até este momento trata ou de um modelo ou de outro; ou analisam uma instituição específica e sem articulação com as demais. Entende-se que é preciso então articular essas pesquisas e aprofundar nas particularidades dos dois modelos para a compreensão do processo empreendido nas instituições educativas confessionais femininas brasileiras no período aqui proposto. 


\section{A EDUCACÃO FEMININA EM CONVENTOS E RECOLHIMENTOS CATÓLICOS DA AMÉRICA PORTUGUESA}

Os conventos e recolhimentos caracterizavam-se como dois tipos de instituições católicas para a educação feminina presentes no período colonial brasileiro. Para Leila Algranti (1999), conventos e recolhimentos não apresentavam muitas diferenças. Embora exista uma documentação com denominação e finalidade diferenciada para a aprovação de funcionamento dessas instituições, na prática cotidiana da América Portuguesa, verifica-se que os dois modelos acabavam exercendo funções muito próximas, apenas diferenciando-se em seu aspecto legal e na condução dos votos proferidos pelas reclusas. A fundação dos recolhimentos era mais facilitada pelo fato de ser exigida somente uma licença episcopal para o seu funcionamento, enquanto os conventos necessitavam ainda de uma ordem papal e da aceitação da ordem religiosa na qual a instituição desejava ingressar.

Uma ordem se constitui em um agrupamento de religiosos em que os membros fazem os votos solenes (obediência, pobreza e castidade). As origens, as características e as organizações das ordens variam, mas certos traços são comuns, uma vez que elas compreendem muitas casas, que geralmente são autônomas em sua administração, tendo como regente um abade ou uma abadessa, no caso de uma instituição feminina. Cabe ao papa decidir se a ordem religiosa será submissa ao papado ou ao bispado local. Todas as ordens seguem uma Regra que dita os seus costumes (GERHARDS, 1998). As regras, instituídas geralmente pelos fundadores, podem ser consideradas como condutoras do cotidiano dentro dos espaços compreendidos pelos Conventos ou Recolhimentos, e, além de estabelecerem o caminho das suas práticas em todas as horas do dia, também apontam as diretrizes educativas dos grupos que se recolhem nesses espaços, especialmente em relação às mulheres enclausuradas.

Entre os séculos XI e XIII, a prática do claustro já estava estabelecida e devia ser cada vez mais observada, assim como os princípios estabelecidos para cada ordem religiosa. Embora distantes do mundo terreno, as monjas dependiam sempre dos religiosos masculinos, já que necessitavam de homens para a administração da Casa, para o contato com o mundo exterior e, ainda, de confessores e padres que celebrassem missas.

A partir do século XVI, observa-se que a ampliação do número de mulheres que procuravam viver em comunidade religiosa foi crescente. Segundo Leila Algranti (1999), a ampliação da procura 
ia também ao encontro das conturbações do mundo moderno e das novas necessidades vivenciadas por diversas categorias femininas. A prática de enclausuramento assumiu não só um papel de espaço de devoção, mas também um caráter punitivo contra mulheres infratoras, ou recolhimento de mendigas e pobres, ou ainda das representantes da nobreza e da alta burguesia, especialmente aquelas que não dispunham de proteção masculina ou um dote para o casamento.

$\mathrm{Na}$ Reforma Católica do período moderno, o Concílio de Trento (1545-1563) ocupou-se particularmente com as ordens religiosas. Foi um marco para assegurar os caminhos dos Conventos a partir daquele momento. Informava a necessidade de obedecer às regras específicas de cada Ordem e colocava alguns princípios que seriam observados por todos os regulares. (CONCÍLIO DE TRENTO, Cap.V, Sessão $\mathrm{XXV}, 1563)$. No caso das mulheres, instituiu que as enclausuradas deveriam confessar e receber a eucaristia uma vez por mês, podendo então abrir suas portas para o confessor que seria encarregado de administrar também o sacramento. Quanto à vocação feminina para a vida religiosa, esta deveria ser observada a partir dos 12 anos de idade e também após a verificação da virgindade da postulante. Além disso, assegurava que ninguém proibiria ou obrigaria a mulher para a vida religiosa, já que esta seria uma vocação e apenas desejada por Deus (CONCÍLIO DE TRENTO, Cap. XVI, Sessão XXV, 1563).

Segundo Gabriella Zarri (2007), a partir do concílio tridentino, especialmente para o universo feminino, a clausura tomou cada vez mais um valor de proteção e separação, mas também se tornou um espaço de disciplinamento dos corpos e dos pensamentos. Por outro lado, propiciava o acesso ao conhecimento por meio de práticas de leitura e escrita e o distanciamento do controle familiar. $\mathrm{O}$ espaço da clausura se dividia em celas individuais para as irmãs e espaços comunitários para orações, trabalhos manuais e refeitório. Todos os momentos de recreação deveriam acontecer nos jardins do interior do claustro. A porta da clausura teria uma vigilância constante e somente pessoas autorizadas pelo bispo ou pároco local poderiam ter acesso ao espaço. Além disso, o controle sobre as conversas, orações e demais atividades acontecia por meio da Regra.

Embora o espaço de reclusão tenha orientações tridentinas e especificidades instituídas pelas regras, quando é possível analisar as especificidades de cada instituição, verifica-se certa permeabilidade nas relações no interior das clausuras (ZARRI, 2007). Ao analisar os conventos e recolhimentos que existiram na região sudeste da América Portuguesa, Leila Algranti (1999) informa que eles receberam diversos 
tipos de mulheres, com diferentes intenções para sua reclusão, como, por exemplo, além das devotas, viúvas, mulheres em conflitos matrimoniais com os seus maridos, educandas, etc. Segundo a autora, "embora os objetivos dos estabelecimentos fossem traçados no momento de suas fundações, era a prática cotidiana que se encarregava de imprimir o contorno dos estabelecimentos e os rumos a serem seguidos pelos seus habitantes" (ALGRANTI, 1999, p. 79).

Torna-se necessário questionar quem foram essas mulheres que procuraram recolher-se em um modo de vida conventual, uma vez que os recolhimentos podiam abrigar mulheres de variada qualidade e condição, enquanto os conventos recebiam, geralmente, mulheres da elite colonial. Os recolhimentos eram de quatro tipos: "para meninas", que recebiam índias, órfãs ou aquelas separadas da família por algum motivo, até a idade do casamento; "para moças ou mulheres decaídas", aquelas rejeitadas pela sociedade e arrependidas, também chamadas de "madalenas"; "para mulheres desejosas de uma vida na oração e na penitencia", viúvas ou abandonadas pelos maridos que não portavam hábito religioso, nem seguiam regra ou clausura; finalmente, as "mulheres destinadas à vida monástica", que se organizavam nos moldes conventuais, com clausura, hábito religioso e seguiam uma determinada regra (AZZI; RESENDE, 1983, p. 30-31). Embora, em alguns casos, detecte-se que tenha havido instituições que abrigavam um tipo de recolhida específico, na maioria dos recolhimentos que existiram na América Portuguesa, foram recebidos vários tipos de recolhidas. Por meio da análise da obra de Riolando Azzi e Valéria Resende (1983), é possível traçar o Quadro 1, acerca dos conventos e recolhimentos que foram fundados no período colonial brasileiro:

QUADRO 1 - Recolhimentos e conventos da América Portuguesa

\begin{tabular}{|l|l|l|}
\hline Local & Recolhimento/provável data de Início & Convento/ data de Início \\
\hline Olinda/Pernambuco & $\begin{array}{l}\text { Recolhimento de mulheres da Ordem } \\
\text { Terceira Franciscana/1576 }\end{array}$ & \\
\hline Olinda/Pernambuco & Recolhimento da Conceição/1595 & \\
\hline Salvador/Bahia & Convento do Desterro/1677 \\
\hline São Paulo/São Paulo & Recolhimento de Santa Teresa/1685 & \\
\hline $\begin{array}{l}\text { Rio de Janeiro/Rio de } \\
\text { Janeiro }\end{array}$ & Recolhimento da Ajuda/1687 & Convento da Ajuda/1750 \\
\hline Macaúbas/Minas Gerais & $\begin{array}{l}\text { Recolhimento de Nossa Senhora da } \\
\text { Conceição de Monte Alegre/1716 }\end{array}$ & \\
\hline
\end{tabular}




\begin{tabular}{|c|c|c|}
\hline Salvador/Bahia & $\begin{array}{l}\text { Recolhimento Senhor Bom Jesus dos } \\
\text { Perdões/1723 }\end{array}$ & \\
\hline Salvador/Bahia & $\begin{array}{l}\text { Recolhimento das Ursulinas da } \\
\text { Soledade/1739 (coração de Jesus) }\end{array}$ & $\begin{array}{l}\text { Convento das Ursulinas da } \\
\text { Soledade/1741 }\end{array}$ \\
\hline Salvador/Bahia & & $\begin{array}{l}\text { Convento das Ursulinas das } \\
\text { Mercês/1742 }\end{array}$ \\
\hline $\begin{array}{l}\text { Rio de Janeiro/Rio de } \\
\text { Janeiro }\end{array}$ & Recolhimento do Desterro/1742 & $\begin{array}{l}\text { Convento de Santa } \\
\text { Teresa/1780 }\end{array}$ \\
\hline Salvador/Bahia & & $\begin{array}{l}\text { Convento da Conceição da } \\
\text { Lapa/1744 }\end{array}$ \\
\hline Igaraçu/Pernambuco & $\begin{array}{l}\text { Recolhimento do Sagrado Coração de } \\
\text { Jesus/1744 }\end{array}$ & \\
\hline $\begin{array}{l}\text { Minas Novas/ Santa Cruz } \\
\text { da Chapada/ Minas Gerais }\end{array}$ & $\begin{array}{l}\text { Casa de Oração do Vale de Lágrimas/1750 } \\
\text { ou Recolhimento de Sant'Ana da } \\
\text { Chapada/1780 }\end{array}$ & \\
\hline São Luís/Maranhão & $\begin{array}{l}\text { Recolhimento das Ursulinas do Sagrado } \\
\text { Coração/1752 }\end{array}$ & \\
\hline Salvador/Bahia & $\begin{array}{l}\text { Recolhimento de São Raimundo } \\
\text { Nonato/1755 }\end{array}$ & \\
\hline São Paulo/São Paulo & Recolhimento da Luz/1773 & \\
\hline Recife/Pernambuco & Recolhimento da Glória/1777 & \\
\hline $\begin{array}{l}\text { Santo Amaro da } \\
\text { Purificação/Bahia }\end{array}$ & $\begin{array}{l}\text { Recolhimento para mulheres } \\
\text { arrependidas/1807 }\end{array}$ & \\
\hline Sorocaba/São Paulo & $\begin{array}{l}\text { "Convento" Imaculada Conceição de Santa } \\
\text { Clara/1811 }\end{array}$ & \\
\hline
\end{tabular}

Fonte: AZZl; RESENDE, 1983.

Como os recolhimentos surgiram de forma espontânea, tornase difícil detectar o início de seu funcionamento e, portanto, parte-se das prováveis datas de fundação. Por outro lado, não é possível afirmar que existiram apenas essas instituições na América Portuguesa, uma vez que muitas podem ter existido e nunca ter solicitado permissão de funcionamento para a Coroa ou, ainda, para os bispados aos quais estariam vinculadas. $\mathrm{Na}$ análise do quadro acima, detecta-se um número superior de recolhimentos em relação ao de conventos. O primeiro tipo soma 15 instituições, das quais apenas duas conseguiram transformarse em convento ainda no século XVIII. Outros quatro recolhimentos, que sobreviveram por mais tempo, conseguiram a passagem para a categoria de convento apenas no século $\mathrm{XX}^{2}$. Por outro lado, notase que os conventos setecentistas foram fundados nas cidades mais 
importantes da colônia, nas principais sedes administrativas e que concentravam uma forte presença da elite, quatro deles em Salvador e dois no Rio de Janeiro.

A dificuldade em alcançar a regulação oficial das instituições femininas por parte do poder político justifica o número superior de recolhimentos. Em um primeiro momento, é possível identificar a necessidade de canalizar a população feminina para o casamento e o povoamento do território, tornando o incentivo ou a proibição da abertura dos conventos e recolhimentos temas centrais das preocupações demográficas da Coroa Portuguesa e, por isso, geralmente as instituições eram primeiramente fundadas e depois regulamentadas. Por outro lado, deve-se atentar para o fato de alguns pais que aqui residiam preferirem encaminhar as suas filhas para conventos portugueses em vez de casá-las com homens que eram considerados abaixo de sua condição social, ou quando ainda não possuíam riquezas suficientes para os dotes matrimoniais de suas filhas. O envio para as instituições devocionais acarretaria não só a solução desses problemas, como ainda a possibilidade de dotá-las de algum conhecimento devocional e o alcance de dádivas celestes para toda a família, pois era considerado uma honra ter uma devota na família. Devido às dificuldades de transporte das moças para os conventos portugueses e ainda aos custos dessa empreitada, os soteropolitanos foram os primeiros a solicitar a abertura do primeiro convento em solo brasileiro, o qual foi fundado em 1677 e se encontra em funcionamento até os dias atuais.

A historiografia trata o Convento de Santa Clara do Desterro em suas especificidades, ou remete a episódios que aconteceram naquela instituição ${ }^{3}$, ou discute o cotidiano das irmãs e retratam os desvios encontrados no convento ${ }^{4}$. No recorte desta pesquisa, pretende-se analisar o caráter educativo no interior desse convento, o qual se vinculava à ordem das irmãs clarissas, cuja primeira Regra foi aprovada em 1247 e já previa pelo menos o domínio da leitura por parte de suas enclausuradas. Essa prática era necessária para as recitações nos momentos do Ofício Divino, e a observância de determinadas orações em horários específicos. Geralmente os textos para a oração nos momentos do Ofício Divino vinham em latim e estavam contidos nos livros designados como Breviários. As religiosas que sabiam ler deveriam utilizar o Breviário e as demais ocupariam o tempo com orações estipuladas pela Regra.

A obra Espelho de perfeytas religiosas, de 1718, publicada em Portugal pelo padre franciscano José de Jesus Maria, aponta como deveria ser o cotidiano das clarissas na busca da perfeição religiosa. 
Para o autor, a busca da perfeição seria pelo aprendizado da leitura em latim. Aponta que existiam três tipos de leitoras: aquelas que liam e não compreendiam o latim; aquelas que liam e compreendiam; e ainda aquelas que liam, entendiam e "falavam com Deus". Este último tipo seria o ideal para alcançar a perfeição religiosa.

Dentro de um mosteiro de clarissas, as religiosas dividiamse em duas categorias: irmãs de "coro", por saberem ler e irmãs "conversas", que não sabiam ler. A distinção do conhecimento da leitura aparece até nos hábitos trajados pelas irmãs, uma vez que aquelas do coro usavam um véu preto e as conversas um véu branco. Considerava-se que aquelas que não possuíam a habilidade da leitura, as irmãs conversas, também participavam de certo conhecimento religioso, uma vez que deveriam decorar determinadas orações e seguir todas as orientações da regra. (MARIA, 1718). Nesse sentido, ler significava entrar em contato com a letra dos textos impressos ou manuscritos, sendo que a escrita pressupunha a decifração e a reprodução da letra escrita e, portanto, as mulheres enclausuradas desenvolviam essas habilidades de forma diferenciada.

$\mathrm{Na}$ análise das práticas de leitura e escrita no Convento do Desterro, torna-se necessário ressaltar que essa era uma instituição que valorizava o ensino da leitura, uma vez que a presença de irmãs de véu preto era constante em seus quadros. O documento papal de autorização da instituição, datado de 1669, já aponta o controle sobre a quantidade de irmãs que poderiam ter o conhecimento da leitura do breviário, uma vez que instituía-se

[...] hum mosteiro para cincoenta Freyras com Abbadeça, ou Prioreça trienal, as quaes guardem a segunda Regra de São Francisco, chamadas Urbanas, e tragão véo negro, e estejao sujeitas á jurisdiçao do ordinário do Brazil, com a assignação de oito mil cruzados de renda annuaes. -E que possao ser admittidas no mesmo Mosteiro tantas Freyras conversas, quantas pedir a razão, e parecer conveniente. (CLEMENTE IX apud JABOATÃO, 1858, p. 634)

É possível perceber a necessidade do papa de delimitar o número de mulheres, 50, que poderiam portar o véu negro e, logo, celebrar o Ofício Divino, como uma espécie de controle sobre o domínio da leitura. Não demonstra uma preocupação com o número de irmãs de véu branco, as conversas, uma vez que essas poderiam ser convenientes à empreitada de expansão da reclusão feminina na América Portuguesa aos olhos da Igreja. Ressalta-se a hierarquização das clarissas, propiciando então a detenção de um status no interior do claustro, entre irmãs de coro e conversas. 
As ordens religiosas que recebiam as mulheres de vida perfeita, como o caso das clarissas que fundaram o Convento do Desterro, obedeciam a uma determinada regra, mas viviam em comunidades independentes, sem qualquer ligação ou dependência com as outras Casas da Ordem, e cada comunidade ou Casa tinha sua própria Superiora, regente ou abadessa. Por isso, cabiam às quatro irmãs originárias do Convento de Évora e que fundaram a instituição aqui analisada as funções necessárias para a abertura de um convento: uma seria abadessa, outra sacristã-mor e porteira, outra vigária do coro e mestra das noviças e, finalmente, a escrivã. Todas deveriam portar véu preto para conduzir a formação de noviças e, consequentemente, novas irmãs.

Em sua memória do Convento do Desterro, a primeira escrivã, Sóror Maria do Raimundo, narra a longa viagem entre Évora e Salvador, as dificuldades da instalação e a chegada das primeiras noviças à casa. Em 1678, a escrivã tornou-se mestra das noviças, sendo que as primeiras 14 noviças aceitas no convento baiano foram instruídas para compreender os princípios da ordem propostos pela fundadora e, segundo a mestra, só alcançariam a verdadeira doutrina religiosa se fossem bem instruídas na religião e nos princípios das irmãs clarissas (RAIMUNDO, 1684 citado por JABOATÃO, 1858, p. 659-660). Verifica-se, portanto, que uma determinada educação religiosa fazia parte do cotidiano do convento desde a sua fundação e o aprendizado da leitura e do latim era necessário para a formação religiosa proposta pela Ordem.

Ser educanda no Convento do Desterro significava ser vocacionada para a vida religiosa. As ingressantes seriam moças brancas e donzelas, com no mínimo 6 para 7 e, no máximo, 25 anos. Ao ingressar "[...] prometiam servir a Deus, observar as leis da clausura, serem sustentadas pelos seus pais ou parentes" (NASCIMENTO, 1994, p. 121). Verifica-se que, desde o início da instituição, foram aceitas meninas e mulheres de diversas idades, solteiras ou viúvas, e que pertenciam às melhores famílias da Bahia, de Sergipe e Pernambuco. As pressões acerca da ampliação do número de mulheres de véu preto na instituição foram constantes, uma vez que portar essa indumentária no claustro demonstrava prestígio em seu interior. É importante salientar que a educação acontecia em/para o interior dos claustros, uma vez que não havia a intencionalidade de retorno das mulheres para a vida exterior. Era uma educação devocional, controlada pelos superiores masculinos e com finalidade de perpetuação do controle e do caráter para a busca de uma determinada perfeição religiosa. 
Segundo Filipe Costa (2006), os séculos XVI e XVII são considerados como aqueles que propiciaram a maior ampliação da abertura de conventos femininos, envolvendo misticismo, penitência, contemplação e união espiritual entre as reclusas. Trata-se de uma “[...] procura completada com a oração, em particular na devoção dos santos, na procura da revelação direta de Deus ao Homem através de modelos de virtude e santidade, na base do fenômeno do renascimento monástico deste período" (COSTA, 2006, p. 22). Já a segunda metade do século XVIII será marcada por um resfriamento do fenômeno e um declínio da vida conventual, marcada especialmente pelas adaptações das instituições às necessidades e aos anseios das sociedades locais, aos tipos diferenciados de mulheres que procuravam recolher-se e das práticas desviantes daquelas regras instituidas pelas ordens religiosas. Somam-se a isso a ampliação do discurso acerca da educação feminina e um novo modelo educativo proposto pela Igreja em expansão: os colégios administrados pelas congregações católicas.

\section{AS ESCOLAS FEMININAS DE FREIRAS DO SÉCULO XIX}

Embora o movimento congreganista educativo europeu estivesse em expansão desde o final do século XVIII, será na segunda metade do século XIX que as religiosas congregadas de vida ativa aportaram no Brasil. As congregações, aprovadas pelo papado, se distinguem das religiosas de vida perfeita, aquelas conventuais reclusas e analisadas até aqui, por não proferirem votos perpétuos, mas apenas votos simples ou de obediência, renováveis em períodos determinados pelas respectivas regras. Também não são mulheres enclausuradas, uma vez que exercem diversas atividades fora de suas casas, tais como cuidar de doentes, prisioneiros e órfãos, e, especialmente no século XIX e primeira metade do século XX, se encarregam da escolarização de meninas. É importante salientar que o modelo conventual continuou coexistindo com o modelo congreganista, mas o primeiro foi perdendo cada vez mais adeptas e passou a receber apenas mulheres que desejavam a reclusão devocional, enquanto o segundo expandia-se por meio da implantação da escolarização de meninas, em uma perspectiva de educá-las para o mundo externo, especialmente para o futuro matrimônio e a maternidade.

Além disso, a diferenciação encontra-se ainda no fato que as ordens religiosas, que recebiam as mulheres de vida perfeita, obedeciam a uma determinada regra, mas viviam em comunidades independentes, sem qualquer ligação ou dependência com as outras Casas da ordem, 
e cada comunidade ou Casa tinha a sua própria Superiora. Já as congregações de vida ativa caracterizavam-se por um misto de práticas sociais e religiosas, sendo que as mulheres poderiam circular pelas cidades e possuíam uma Superiora Geral no local de fundação da congregação.

Conforme analisa Claude Langlois (1984), a Revolução Francesa no final do século XVIII foi responsável por modificar o predomínio do modelo de religiosas reclusas e que seguiam determinadas ordens. A revolução destruiu abadias, conventos, mosteiros, mas permitiu, por outro lado, o fortalecimento e o surgimento de determinadas congregações femininas, aptas a responder às necessidades da sociedade naquele momento, no cuidado com os seus presos, doentes de guerra e órfãos. Passadas as adversidades da revolução, as congregações femininas francesas conheceram um processo de expansão, especialmente na primeira metade do século XIX. Ao analisar a expansão das congregações femininas francesas no século XIX, Claude Langlois (1984) considerou que aquele foi o momento da mobilidade congreganista, que tanto significou a ampliação e a instalação de novas congregações em outros territórios quanto a construção de novas Casas e ainda a multiplicação do número de religiosas.

Segundo Gibson (1993), o século XIX pode ser considerado não só como o momento da feminização da devoção, por meio da ampliação ao culto de Nossa Senhora, mas também como da feminização do catolicismo na França, considerado tanto pela ampliação do número de mulheres devotas que frequentam as igrejas, como pela fundação de associações leigas caritativas ou pela expansão do número de congregações femininas.

Foram três os motivos determinantes para o sucesso e a expansão das congregações femininas francesas no século XIX: a capacidade de adaptação desse modo de vida religioso aos lugares de instalação; a eficácia das congregações em dar respostas às necessidades da sociedade; e a possibilidade de articular o mundo urbano com o campo, já que transitavam entre os dois. As congregações se multiplicavam e prosperavam porque possuíam um modelo simples: uma forma facilmente controlável da vida religiosa e um instrumento eficaz para agir sobre a sociedade. Por outro lado, cabe salientar os diversos conflitos políticos liberais que existiram no continente europeu no século XIX, o que propiciou a saída de muitas mulheres congregadas da Europa.

É importante salientar que o impulso das congregações na primeira metade do século XIX coincidiu com a ampliação do discurso acerca da necessidade da educação feminina. Dentro do seu 
potencial de adaptação às necessidades sociais, as freiras responderam então às necessidades de criação de escolas femininas. O sucesso das congregações no meio feminino deveu-se principalmente ao fato de se oferecerem possibilidades de trabalho, mobilidade no interior da França e no exterior, assim como postos de comando impensáveis para outras mulheres no século XIX. Nesse meio, as mulheres encontravam estabilidade e respeitabilidade. Eram recrutadas em todas as classes sociais: mulheres das elites, mas também pobres e, especialmente, camponesas. Estas, que não dispunham nem de riqueza para o dote nem de muito saber, eram relegadas aos trabalhos mais pesados dentro das congregações, principalmente nas atividades manuais. Tais atividades e o pertencimento a uma Congregação possibilitavam uma distinção social, particularmente para as mulheres pobres.

Segundo Ivan Manoel (1996), no século XIX ocorreu uma preparação de agentes sociais com a ampliação e a circulação das congregações e, particularmente, da educação confessional feminina. Em um momento de perda de fiéis para a "modernidade", a ampliação das escolas comandadas por freiras fazia parte de um movimento bem planejado pela Igreja Católica de "recristianização" por meio da educação feminina. A Igreja criava uma estratégia de "teoria dos círculos concêntricos": partindo da educação cristã das mães pelas mãos das freiras, pretendia-se cristianizar os seus filhos, que seriam responsáveis pela cristianização de suas famílias e, em escala mais ampliada, das sociedades cristãs (MANOEL, 1996, p. 49).

As Filhas de Caridade de São Vicente de Paulo, que fundaram o primeiro colégio de freiras em solo brasileiro (1849), foram grandes mediadoras do discurso católico, principalmente por meio da educação feminina. O Padre Etienne, Superior Geral da Congregação da Missão ${ }^{5}$, compreendia que a educação feminina tornava-se a principal missão das Filhas de Caridade de São Vicente de Paulo. Aos seus olhos, a missão educativa, especialmente de mulheres, multiplicaria os fiéis e fortaleceria a Igreja Católica Romanizada por meio da formação das alunas:

Mas, se a missão foi importante em todos os tempos, minhas queridas filhas, ela se tornou muito mais no tempo em que vivemos. A vontade de Deus torna-se evidente hoje, e tudo indica que Ele reserva à Companhia um destino enorme e magnífico nesta matéria. (...) Se vocês forem fiéis à graça de sua santa vocação, terão a certeza de que fornecerão para a igreja a conversão de uma multidão de infiéis e hereges, e que irão ampliar o reino de Jesus Cristo. Já não podemos duvidar, pois vemos que todos os lados estão chamando a missão de vocês, especialmente para confiar a vocês a educação de meninas. (PADRE ETIENNE, 1866, tradução livre, grifos meus) 
O pensamento da Igreja Católica no século XIX estava centrado principalmente nas propostas ultramontanas, movimento também conhecido como Catolicismo Romanizado. Do latim ultramontanus, o termo designou aqueles fiéis que atribuíam ao Papa um importante papel na direção da fé e no comportamento do homem. A defesa das ideias ultramontanas pode ser encontrada em diversos documentos produzidos ao longo do século XIX com a intencionalidade de expressar o pensamento predominante nos quadros eclesiásticos da época, além de pretender doutrinar os fiéis, quando o mundo moderno, secularizado, constituía-se em um grande perigo para a salvação da alma, pois se fundamentava principalmente na liberdade política e também de pensamentos. Era um mundo que não obedecia aos preceitos católicos e ao controle da Igreja. Tal controle só retornaria com a implantação e a aceitação dos princípios ultramontanos e, principalmente, numa estrutura articulada pela manutenção e pelo fortalecimento do controle do sistema educacional, especialmente por meio da educação feminina. As Irmãs vicentinas, mas também as demais congregações religiosas que chegaram ao solo brasileiro depois delas, tornaram-se mediadoras da expansão do discurso católico por meio da educação feminina.

Com relação às irmãs vicentinas, a Regra proposta pelo fundador instituía que elas não eram religiosas e não pertenceriam ao clero regular, já que os seus diversos trabalhos eram incompatíveis com as particularidades das mulheres que seguiam horários definidos e passavam a maior parte do tempo orando nas clausuras (REGRAS COMUNNS, 1821). Por outro lado, também não possuiriam espaço definido para habitar e dependeriam da atividade que exerceriam naquele momento; mas deveriam portar-se com modéstia e virtude como as religiosas enclausuradas. Como não eram consideradas religiosas regulares, mas viviam em uma companhia secularizada, também não faziam votos solenes, sendo que os votos seriam renovados anualmente, possibilitando assim a renovação ou o afastamento das atividades caritativas, tornando-as livres para deixar a instituição a cada ano (MAYNARD, 1860).

A Congregação das Filhas de Caridade de São Vicente de Paulo, considerada a primeira congregação feminina a chegar ao Brasil, fundou a sua obra em 1849, na cidade mineira, Mariana. Entre as suas diversas atividades, estabeleceram o Colégio Providência para as meninas ricas, em funcionamento até os dias atuais. As freiras preocuparam-se desde o início em cuidar de doentes, de idosos desamparados e ainda introduziram a educação tanto para as meninas 
de famílias abastadas, quanto para as meninas pobres ou órfãs. Porém, ao longo da história da presença das vicentinas em Mariana, acentuou-se a diferenciação no cuidado dos grupos de educandas: em um prédio ficavam as pensionistas pagantes e algumas pobres gratuitas, financiadas pelas subvenções provinciais; em outro prédio, ficava o grupo das órfãs; em outro, o grupo de doentes e idosos.

As Irmãs aceitaram na instituição meninas pagantes tanto para prover as necessidades financeiras das demais atividades quanto para auxiliar na formação das jovens mineiras. Inicialmente a Irmã Dubost, primeira superiora das vicentinas, relacionava a aceitação das pagantes às necessidades locais e à ausência de pessoas aptas para educar as meninas da elite mineira. Com o fortalecimento da instituição educativa, a mesma superiora via a educação como a grande ação das vicentinas no Brasil: "Insisto ainda [...], para afirmar que a educação da juventude é a obra mais importante e acrescento que o bom Deus, tendo aberto por este meio, uma porta para as Irmãs no Brasil, parece querer que esta obra permaneça a obra das Irmãs" (IRMÃ DUBOST, 21/03/1854, In: História da Missão).

Salienta-se ainda que a educação da elite feminina fundamentase em um movimento maior: a ampliação do discurso da necessidade de educar as mulheres; a falta de escolas e colégios para este segmento não só em Minas Gerais, mas no Brasil, em geral; e a intenção dos pais de proporcionar uma educação específica para as suas filhas. Por outro lado, as Irmãs necessitavam dos pagamentos efetuados por esse grupo para manter as suas obras caritativas e complementares à obra das vicentinas no Brasil.

O primeiro documento que fala das possíveis disciplinas que seriam adotadas no Colégio das Filhas de Caridade em Mariana tratava-se de uma consulta à Superiora em Paris, embora a Irmã Dubost já considerasse as necessidades locais: "Segundo disse o Pe. Visitador sobre a mentalidade do país, parece que os pais muito se interessam em que os filhos saibam ler, escrever e falar seu idioma. Que conheçam um pouco de aritmética e também de geografia. Que pensais deste programa?” (IRMÃ DUBOST, 23/07/1849, In: História da Missão). Verifica-se que a perspectiva inicial de ensino, além de contemplar os desejos dos pais, compreendia um número mínimo de disciplinas e não se distanciava muito do ensino proposto nas escolas públicas de primeiras letras da época. Mas logo os pais das alunas pagantes passaram a exigir a inserção de determinadas disciplinas que aproximassem o ensino na instituição de uma educação "refinada", nos moldes da "civilidade", como o aprendizado do desenho, 
da língua francesa, bordados e música, mais especificamente, do piano. A inserção dessas disciplinas no currículo da escola pode ser verificada no decorrer do fortalecimento da instituição na oferta para as alunas pagantes. O domínio da prática do piano era visto como um diferencial nas atividades discentes, que foram assim avaliadas pelo diretor da Instrução Pública de Minas Gerais:

[...] Admiráveis escriptas de diversas formas, ornadas de variados desenhos, nítidas e perfeitas copias de Cartas Geográficas, flores, obras de ponto de marca, bordados primorosos, tanto de linha, como de retroz e fios de seda, trabalhos já convertidos em objectos de uso, taes como: bonets, palletós, sapatos de tapete etc. etc. [...] Por esta occasião também se fizerão ouvir algumas musicas de canto, e peças de piano, que pela graça e perfeição com que forão executadas, comprovão o estado de adiantamento das Alumnas neste apreciável ramo da educação do bello sexo. (Relatório do diretor da Instrução Pública, Joaquim Delfino Ribeiro da Luz, 11/03/1856, grifos nossos).

Para o representante do poder provincial mineiro, cabia às alunas o aprendizado das letras perfeitas, de trabalhos manuais nos moldes franceses e de músicas cantadas e tocadas ao piano. Esses eram os aprendizados que desejavam para uma menina da elite naquele momento: uma educação literária, musical, moral e também de prendas domésticas, enfim, uma educação que as preparasse para circularem nos salões da sociedade da época e também se transformarem em ótimas esposas e mães nos moldes do catolicismo.

Além do Colégio Providência, em outro prédio e com educação diferenciada das alunas pagantes, ficava o Colégio das Órfãs, que era mantido pelos auxílios da população local e do governo provincial, além da venda de trabalhos manuais produzidos pelas alunas. Ali as órfãs eram preparadas tanto para trabalhos futuros, com a confecção de artefatos que poderiam ser comercializados, quanto para exercer a função de professoras. "No Collegio das orphãs há 58 meninas desvalidas, que, com esmero, recebem instrucção e educação, e algumas das quaes já occupão cargos de magisterio na Província." (Relatório do Diretor Geral da Instrução Pública, José Aldrete de Mendonça Rangel de Queiroz Carreira, em 30/01/1882)

Verifica-se que, já na década de 1850, estava bem nítida a formação das três instituições que seriam administradas pelas Filhas de Caridade em Mariana: o Colégio Providência, com meninas pagantes e aquelas pobres mantidas com o auxílio das subvenções provinciais; o Colégio das Órfãs; e o asilo das mulheres pobres e inválidas. Este último era autossustentável, uma vez que as recolhidas produziam diversas flores artificiais, bordavam toalhas e enxovais que, 
vendidos, proporcionavam recursos suficientes para a manutenção da instituição. As Filhas de Caridade desenvolviam práticas educativas diferenciadas de acordo com a condição social da educanda, com os anseios da sociedade local e as orientações da própria congregação. Assim, atendiam à diversidade do público feminino e propiciavam caminhos e práticas educativas variadas para essas mulheres.

$\mathrm{Na}$ análise de outras instituições conduzidas por congregações que foram instaladas em solo brasileiro, torna-se importante salientar que era uma prática comum a proposta de uma educação diferenciada para os grupos sociais que atendiam: de um lado as meninas de elite ou aquelas financiadas pelo poder público, ou ainda por uma madrinha rica; de outro lado, órfãs e/ou pobres que não tinham condição de pagar. Cabia às alunas pagantes o aprendizado moral e de determinados dons necessários para a inserção e a circulação na sociedade da época, como a demonstração do conhecimento do francês, de boas maneiras à mesa, na fala, nas vestes, nas atividades de bordado, de canto e no domínio do piano. Por outro lado, cabia às alunas não pagantes o aprendizado moral e de atividades do mundo do trabalho de uma casa, como a limpeza, a culinária, o corte e a costura, enfim, algo que possibilitasse uma profissão futura.

O Quadro 2 foi elaborado para o entendimento da expansão das congregações femininas no Brasil e a sua força na educação da população, que poderia acontecer não só por meio da abertura de colégios, mas também pelas diversas atividades que aqui desenvolveram. Para a sua elaboração foram utilizados inicialmente os dados levantados por José Oscar Beozzo (1983, p. 123-124) e, posteriormente, o cruzamento das informações contidas em estudos específicos das instituições e nos diversos sites e blogs mantidos pelas congregações.

QUADRO 2 - Primeiras congregações femininas no Brasil, 1849-1900.

\begin{tabular}{|c|l|l|l|}
\hline Ano & $\begin{array}{c}\text { Primeiro Local de } \\
\text { instalação }\end{array}$ & \multicolumn{1}{|c|}{ Congregação } & Origem \\
\hline 1849 & Mariana, MG & Filhas de Caridade de São Vicente de Paulo & França \\
\hline 1849 & Porto Alegre, RS & Irmãs do Imaculado Coração de Maria & Áustria \\
\hline 1858 & Itu, SP & Irmãs de São José de Chamberry & França \\
\hline 1866 & Olinda, PE & Irmãs de Santa Dorotéia da Frassinetti & Itália \\
\hline 1872 & São Leopoldo, RS & Irmãs Franciscanas da Penitencia e Caridade Cristãs & Holanda \\
\hline 1884 & Belém, PA & Filhas de Santana & Itália \\
\hline 1885 & Uberaba, MG & Irmãs Dominicanas de Nossa Sra. do Rosário de Monteils & França \\
\hline
\end{tabular}




\begin{tabular}{|l|l|l|l|}
\hline 1888 & Rio de Janeiro, RJ & Irmãs de Nossa Senhora de Sion & França \\
\hline 1889 & Alto Alegre, MA & Irmãs Terciárias Capuchinhas de Loano & Itália \\
\hline 1890 & Rio de Janeiro, RJ & Irmãs Franciscanas do Sagrado Coração de Jesus & França \\
\hline 1891 & Rio de Janeiro, RJ & Nossa Sra. da Caridade do Bom Pastor de Angers & França \\
\hline 1892 & Guaratinguetá, SP & Instituto das Filhas de Maria Auxiliadora & Itália \\
\hline 1893 & Andaraí, RJ & Santos Anjos & França \\
\hline 1895 & Florianópolis, SC & Irmãs da Divina Providencia & Alemanha \\
\hline 1895 & Nova Trento, SC & Irmãzinhas Imaculada Conceição & Brasil \\
\hline 1895 & São Paulo, SP & Irmãs Missionárias de São Carlos Barromeu & Itália \\
\hline 1896 & Olinda, PE & Religiosas da Instrução Cristã & Bélgica \\
\hline 1896 & Olinda, PE & Irmãs de São Vicente de Paulo de Gysegem & Bélgica \\
\hline 1896 & Curitiba, Pr & Irmãs de São José de Tarentaise & França \\
\hline 1897 & Petrópolis, RJ & Irmãs de Santa Catarina Virgem e Mártir & Alemanha \\
\hline 1897 & Rio de Janeiro, RJ & Irmãs Carmelitas da Divina Providência & Brasil \\
\hline 1900 & Mococa, SP & Pequenas Irmãs da Divina Providência & Itália \\
\hline 1900 & Piracicaba, SP & Irmãs Franciscanas do Coração de Maria & Brasil \\
\hline 1900 & Curitiba, Pr & Irmãs Apóstolas do Sagrado Coraccão de Jesus & Itália \\
\hline
\end{tabular}

Fonte: BEOZZO, 1983.

Verifica-se que vieram 24 congregações neste período: oito francesas, sete italianas, duas alemãs, duas belgas, uma holandesa e outra austríaca. Além destas, três congregações foram fundadas no Brasil. A mobilidade dessas freiras parte tanto das necessidades de afastamento de seus territórios de origem por problemas políticos quanto dos anseios da população nos locais de instalação pelas obras congreganistas, que abarcavam não somente a abertura de escolas femininas, como também o trabalho em hospitais, asilos e prisões. Por outro lado, observa-se um número significativo de irmãs francesas e italianas, sendo que as primeiras eram valorizadas em solo brasileiro principalmente por conta dos anseios de implantação de uma educação nos moldes da civilidade francesa, e a segunda, por conta do grande afluxo de italianos no movimento colonizador após a abolição da escravatura no Brasil. Observa-se ainda que a entrada das irmãs passou a expandir especialmente após a proclamação da República (1889) uma vez que não dependia mais do controle governamental para a autorização das entradas. Oscar Beozzo (1983), ao analisar as congregações femininas, aponta que durante a Primeira República Brasileira (1889-1930), “[...] são fundadas no Brasil ou chegam aqui 
dos vários países da Europa e mesmo de alguns outros países situados fora do continente europeu, 93 congregações." (BEOZZO, 1983, p. 127). Considera-se que esse movimento mais geral da expansão das congregações, desde o século XIX, abarcando toda a primeira metade do século XX, ainda deve ser estudado, pois se verificam muitos estudos isolados sobre cada Instituição, e poucos que perfazem o caráter mais geral do movimento congreganista no Brasil.

\section{CONCLUSÕES}

Embora existam diversos estudos acerca das instituições educativas confessionais femininas fundadas no Brasil nos séculos XVIII e XIX, observa-se que a maioria das investigações analisa apenas uma ou algumas instituições específicas, ou não articulam as diferenças e aproximações existentes entre a educação propiciada nos conventos ou recolhimentos do século XVIII e aquela proposta nos colégios de freiras no século seguinte. A aproximação está no fato de a religião estar no centro e ser parte essencial das ações educativas e que podem ser inseridas em uma longa duração temporal. $\mathrm{O}$ Gravissimun Educationes (CONCILIO VATICANO II, 1965), propõe que cabe à família e especialmente à Igreja educar para formar um bom católico. Ao recuar no tempo, observa-se que tanto conventos e recolhimentos quanto colégios de freiras partiam desse princípio para instituir as suas práticas educativas.

As diferenças apresentam-se tanto na estruturação quanto na intencionalidade das propostas educativas no interior das instituições aqui analisadas. Por um lado, o modo de vida conventual estava vinculado às regras de ordens religiosas, instituía a reclusão de poucas mulheres e educava para a leitura dos breviários em momentos do Ofício Divino ou ainda propiciava para algumas a escrita de obras exemplares na busca da perfeita religiosa.

Já as congregações religiosas que viviam para a vida ativa e instituíram os colégios de freiras nos oitocentos educavam um número maior de alunas com a necessidade de prepará-las para o mundo externo, de acordo com os anseios da sociedade da época, uma vez que propunham currículos voltados para uma educação literária, musical, moral e de prendas domésticas, em busca da perfeição para a vida doméstica, como mulheres católicas que se constituíam como futuras esposas e mães. Observa-se que o discurso da Igreja católica com relação à educação feminina no século XIX distancia-se daquele do século anterior, uma vez que interliga os anseios da sociedade de escolarização das meninas, com a perda dos fiéis católicos para as 
políticas liberais. Assim, a utilização das educandas como agentes do discurso católico torna-se um grande instrumento nas mãos da Igreja.

Tanto nos conventos e recolhimentos quanto no interior das congregações e suas escolas, é possível observar práticas educativas diferenciadas para as suas educandas, especialmente quando analisamos as classes sociais. Assim, quando se observam as diferenças entre as irmãs que portam véu preto ou véu branco no interior dos conventos, verifica-se uma diferença de classes e de funções entre as enclausuradas, especialmente com relação ao domínio da escrita e da leitura. $\mathrm{Na}$ mesma direção, é possível detectar as diferenças curriculares para as educandas das congregações religiosas do século XIX: órfãs, pobres ou meninas ricas.

Embora a análise refira-se a tempos e ações diferenciadas por mulheres no interior da Igreja Católica, não é possível deixar de refletir acerca de algo que perpassa os modelos de educação aqui analisados: o controle da Igreja com relação à educação feminina, quer seja por meio de conventos, recolhimentos ou colégios de freiras. Tal controle passa tanto pelas mãos do mundo masculino, aquele que domina a Igreja, como especialmente pela noção de educação que se quer para essas mulheres, na inculcação de valores morais e devocionais.

Voltando ao Concílio Vaticano II (1965), com a Declaração Gravissimum Educationis (Sobre a Educação Cristã), verifica-se que esse documento foi também responsável por reconfigurar os colégios de freiras, que reproduziam um modelo muito bem aceito pela sociedade desde o século XIX, mas que já demonstrava um enfraquecimento da demanda desde os anos 1940. As reflexões de um mundo pós-guerra, urbanizado e capitalista reconfiguravam o modelo de escolarização confessional. Neste momento, observa-se que o modelo educativo proposto pelas antigas congregações não tinha mais sentido e caberia às religiosas renovar a mentalidade e também influenciar mais a sociedade, baseando-se em ideais cristãos. Tal transformação é percebida de uma maneira bem clara nas mudanças ocorridas na forma de vestir das freiras, na aceitação da coeducação, com meninos e meninas nos seus colégios, no decréscimo da quantidade de membros das ordens religiosas e na busca de um novo preparo profissional. "[...] A conveniente renovação da vida religiosa compreende não só um contínuo regresso às fontes de toda a vida cristã e à genuína inspiração dos Institutos mas também a sua adaptação às novas condições dos tempos." (Papa Paulo VI, Perfectae Caritatis, Concílio Vaticano II, 1965) Adaptar, renovar e voltar às origens... mas não perder o domínio e buscar então novos modelos educativos, que não possuem mais a especificidade da educação em Colégios que recebem apenas meninas. 


\section{REFERÊNCIAS}

ALGRANTI, L. M. Honradas e devotas: mulheres da colônia - condição feminina nos conventos e recolhimentos do Sudeste do Brasil (1750-1822). 2. ed. Rio de Janeiro: José Olympio, 1999.

ARAUJO, E. A arte da sedução: sexualidade feminina na colônia. In: DEL PRIORE, M. (Org.). História das mulheres no Brasil. São Paulo: Cia. das Letras, 1997. p. 45-70.

AZZI, R.; REZENDE, M. V. A. A vida religiosa feminina no Brasil colonial. In: AZZI, R. (Org.). A vida religiosa no Brasil: enfoques históricos. São Paulo: Edições Paulinas, 1983. p. 24-60.

BEOZZO, J. O. Decadência e morte, restauração e multiplicação das ordens e congregações religiosas no Brasil (1870-1930). In: AZZI, R. (org.). A vida religiosa no Brasil: enfoques históricos. São Paulo: Edições Paulinas, 1983. p. 85-129.

COSTA, F. Conventos de Freiras: mulheres do século XVIII. Lisboa: Ela por Ela, 2006.

GERHARDS, A. Dictionnaire historique des ordes religieux. Ligugé, Poitiers: Editions Fayard, 1998. p. 442-443

GIBSON, R. Le catholicisme et les femmes em France au XIXe siècle. Revue d'histoire de l'Église de France, Lyon, n. 202, p. 63-93, 1993. Disponível em: < http://www.persee. $\mathrm{fr} / \mathrm{web} / \mathrm{revues} / \mathrm{home} / \mathrm{prescript} / \mathrm{article} /$ pop_0032-4663_1995_num_50_1_5924>. Acesso em: 1 jul. 2015.

LANGLOIS, C. Le catholicisme au féminin: les congrégations françaises à supérieure générale au XIXème siècle. Paris: Editions du Cerf, 1984.

MANOEL, I. A Igreja e a educação feminina (1859-1919): uma face do conservadorismo. São Paulo: Editora UNESP, 1996.

NASCIMENTO, A. A. V. Patriarcado e religião: as enclausuradas clarissas do Convento do Desterro da Bahia. Salvador: Conselho Estadual de Cultura, 1994.

O Convento do Desterro da Bahia. Salvador: Editora Gráfica Industria e Comunicação, s/d.

ZARRI, G. La clôture des religieuses et les rapports de genre dans les couvents italiens (fin XVIe - début XVIIe siècles). Clio: Femmes, Genre, Histoire, Paris, v. 26, p. 01-14, 2007. Disponível em: <https://clio.revues.org/5492>. Acesso em: 1 jul. 2015.

\section{FONTES}

Concílio de Trento. Providências sobre a clausura e custódia das monjas. Cap. V, Sessão XXV. Disponível em: <http://www.veritatis.com.br/area/7>. Acesso em 3 jul. 2009.

Concílio de Trento. O Ordinário deverá examinar a vontade da donzela maior de doze anos, se quiser tomar o hábito de religiosa, e novamente antes da profissão de fé. Cap. XVII, Sessão XXV. Disponível em: <http://www.veritatis.com.br/area/7>. Acesso em: 3 jul. 2009.

MARIA, FR. J. de J. Espelho de perfeytas religiosas: exposição da segunda regra de Santa Clara. Lisboa: Officina de Joseph Lopes Ferreira, 1718. Acervo Biblioteca Nacional de Portugal.

História da missão das Filhas de Caridade de São Vicente de Paulo no Brasil. Casa da Providência, Mariana, 1999. Acervo Arquivo Eclesiástico da Arquidiocese de Mariana.

JABOATÃO, Fr. A. de S. M.. Novo Orbe Seráfico Brasílico ou crônica dos frades menores da província do Brasil. Rio de Janeiro: Typ. Brasiliense de Maximiano Gomes Ribeiro, 1858. 
MAYNARD, M. L. Saint Vincent de Paulo: sa vie, son temps, ses oeuvres, son influence. Paris: Ambroise bray, 1860.

PADRE ETIENNE. Introdution. In: Manuel a l'usage des filles de la charité employées aux écoles, ouvroirs, etc. Paris: Adrien Le Clere, 1866, p. III. Acervo BNF.

CONCILIO VATICANO II. Gravissimum Educationis. Sobre a Educação Cristã. Roma, 1965. Disponível em: < http://www.vatican.va/archive/hist_councils/ii_vatican_council/ documents/vat-ii_decl_19651028_gravissimum-educationis_po.html >. Acesso 15 jul. 2015. PAULO VI. Decreto Perfectae Caritatis. Sobre a conveniente renovação da vida religiosa. In: Concílio Vaticano II. Disponível em: <http://www.vatican.va/archive/hist_councils/ ii_vatican_council/documents/vat-ii_decree_19651028_perfectae-caritatis_po.html>. Acesso em 15 jul.2015.

Relatório do diretor da Instrução Pública, Joaquim Delfino Ribeiro da Luz, 11/03/1856. Disponível em: <http://brazil.crl.edu/bsd/bsd/461>. Acesso em: 22 abr. 2010.

Relatório do Diretor Geral da Instrução Pública, José Aldrete de Mendonça Rangel de Queiroz Carreira, em 30/01/1882. Disponível em: < http://brazil.crl.edu/bsd/bsd/u284/ index.html>. Acesso em: 20 jul. 2009

Regras communs das filhas da caridade e servas dos pobres enfermos. Lisboa, Typographia de Antonio Rodrigues galhardo, 1822. Acervo Biblioteca Nacional de Portugal.

SANTA CLARA. Primeira Regra e vida das senhoras pobres (1247). In: Escritos de Santa Clara. Ordem franciscana. s/d., p. 24. Disponível em: <http://www.editorialfranciscana. org/files/_1_REGRA_4aef87e1542aa.pdf>. Acesso em: 20 set. 2013.

\section{NOTAS}

${ }^{1}$ Chamada Universal - MCTI/CNPq No 14/2014.

${ }^{2}$ Convento de Santa Teresa de São Paulo, SP, em 1913; Mosteiro de Nossa Senhora da Conceição de Macaúbas, MG, em 1926; Mosteiro de Imaculada Conceição de Santa Clara de Sorocaba, SP, em 1929; e Mosteiro da Luz de São Paulo, SP, também em 1929.

${ }^{3}$ Cf. NASCIMENTO, 1994; NASCIMENTO, s/d.

${ }^{4}$ Cf. ARAUjO, 1997.

${ }^{5}$ A Congregação das Filhas de Caridade de São Vicente de Paulo foi fundada em 1633 e teve como líderes Vicente de Paulo e Luisa de Marillac. Em 1625, Vicente de Paulo já havia fundado uma vertente masculina, a Congregação da Missão, cujos padres e irmãos também eram conhecidos como Lazaristas. Além disso, os estatutos das "Filhas de caridade" determinavam a subordinação direta ao Superior dos Padres da Missão.

Submetido: $16 / 09 / 2015$

Aprovado: 13/04/2016

Contato:

Rua Chile, 85.

Apt. 301. Bairro Sion.

Belo Horizonte $|\mathrm{MG}|$ Brasil

CEP. 30.310-670 
